\title{
Nova abordagem tectono-estratigráfica do Supergrupo Espinhaço em sua
}

\section{porção meridional (MG)}

\author{
Farid Chemale Jr. ${ }^{1}$, Ivo Antônio Dussin ${ }^{2}$, Maximiliano Martins ${ }^{2}$, Marcelo Nascimento dos Santos ${ }^{1}$. \\ ${ }^{1}$ IGC-UnB, Brasília-DF, faridchemale@gmail.com, marcelodega@hotmail.com; \\ ${ }^{2}$ DEGEL-CPMTC/IGC/UFMG, Belo Horizonte, MG, ivodusin@yahoo.com.br, maximilianomartins@yahoo.com.br
}

Recebido em 18 de outubro de 2011; aceito em 18 de novembro de 2011

RESUMO: O Supergrupo Espinhaço Meridional é formado por duas grandes sucessões sedimentares separados por nítida discordância angular, interpretada como dois ciclos de preenchimento de bacia: (1) o primeiro Estateriano (1,78 to 1,70 Ga), interpretado como rifte intracontinental, (ii) outro Esteniano-Toniano (1,18 to 0,91 Ga) como uma bacia intracratônica cujo processo inicial de subsidência ocorreu por implantação de um rifte. A ausência de um ciclo bacinal intermediário (1,6 Ga - 1,3 Ga), presente apenas na Chapada Diamantina, permite inferir que a atual região ocupada pela Serra do Espinhaço Meridional comportou-se como um alto estrutural ou área de não deposição.

Palavras-chave: Supergrupo Espinhaço Meridional, geocronologia U-Pb em zircões, ciclos bacinais, evolução tectono-sedimentar.

ABSTRACT: A NEW TECTONO-STRATIGRAPHIC APPROACH FOR THE SOUTHERN ESPINHAÇO SUPERGROUP, MINAS GERAIS STATE. The Espinhaço Supergroup in Southern Espinhaço, Minas Gerais, contains thus two unconformably successions, which can be interpreted as two basin fill cycles: (i) one Statherian (1,78 to 1,71 Ga) as intracontinental rift, (ii) and another Stenian-Tonian (1,18 to 0,91 Ga) as intracontinental rift-sag successor basin. The absence of a intermediary cycle (1,6 Ga-1,3 Ga), present only in Chapada Diamantina (Bahia State), allows to infer that the current region occupied by the Southern Espinhaço Range held like a structural top or area of non-deposition at this time.

Keywords: Southern Espinhaço Supergroup, U-Pb zircon geochronology, basinal cycles, tectono-sedimentary evolution.

\section{INTRODUÇÃO}

A Serra do Espinhaço é um dos principais elementos do relevo brasileiro, sendo um importante divisor de águas na parte oriental do território nacional. As denominações utilizadas para a cordilheira consideram a área de ocorrência de seus diferentes segmentos (Fig. 1), a saber: (i) Espinhaço Meridional que se estende desde as proximidades de Belo Horizonte e prolonga-se ininterruptamente até a região de Olhos D’Água (Minas Gerais); (ii) Serra do Cabral, segmento ocidental da cadeia em Minas Gerais, incluindo a Serra da Água Fria; (iii) Espinhaço Setentrional que se inicia na altura do paralelo $17^{\circ} 30^{\prime} \mathrm{S}$, em Minas Gerais, onde a serra ocorre separada e deslocada por aproximadamente $30 \mathrm{~km}$ na direção NNE da parte Meridional, com prolongamento contínuo do flanco oriental até o Estado da Bahia; (iv) Chapada Diamantina, distribuindo-se inteiramente na porção centro-oriental da Bahia.

O termo Espinhaço tem sido empregado na literatura geológica com três sentidos distintos: geográfico, estratigráfico e geodinâmico (Schobbenhaus, 1993).

A conotação geográfica - Espinhaço Gebirge (Serra do Espinhaço) - foi introduzida por Eschwege (1822) para referenciar a cadeia de serras contínuas e estreitas que se estende segundo o meridiano por mais de 1.200 km, desde o Quadrilátero Ferrífero, em Minas Gerais, até a divisa dos estados da Bahia e Piauí.

No sentido estratigráfico, o Supergrupo Espinhaço compreende metassedimentos de baixo grau metamórfico formados por meta-sequências siliciclásticas, principalmente arenitos associados a psefitos e pelitos, além de rochas carbonáticas e vulcânicas (e.g. Pflug, 1968). A evolução estratigráfica do Supergrupo Espinhaço remonta à Tafrogênese Estateriana, ao redor de 1,75 Ga (Dussin \& Dussin, 1995), com desenvolvimento bacinal ao longo do Meso e talvez do Neoproterozóico (Schobbenhaus, 1993).

O conceito geodinâmico emprega o termo Espinhaço para definir um ciclo de deposição, deformação e metamorfismo no período compreendido entre 1,8 a 1,0 Ga. Neste contexto, o padrão de deformação registrado nos metassedimentos do Supergrupo Espinhaço (incluindo todos os seus segmentos: Meridional, Serra do Cabral, Setentrional e Chapada Diamantina) seria resultante do evento orogenético Espinhaço (ou Uruaçuano), entre 1,3 a 1,0 Ga (e.g. Brito Neve et al., 1979; Almeida-Abreu, 1993, 1995; AlmeidaAbreu \& Renger, 2002; Schobbenhaus \& BritoNeves, 2003). Contudo, a existência de um evento orogenético pós-transamazônico (2,1 a 1,8 Ga) e pré-brasiliano (750 a $530 \mathrm{Ma}$ ) tem sido questionada por diversos pesquisadores (e.g. Uhlein, 1991; Chemale et al., 1991; Dussin \& Dussin, 1995; Uhlein et al., 1995; Danderfer Filho, 2000; Alkmim, 2004). 
Este trabalho apresenta os principais resultados de um projeto de pesquisa desenvolvido na bacia Espinhaço, notadamente em seu segmento mineiro, por meio de levantamentos sedimentológicos/ estratigráficos sistemáticos (Santos et al., em prep.), aliado à geocronologia $\mathrm{U}-\mathrm{Pb}$ em zircões retirados de rochas ígneas e metassedimentares (Chemale Jr. et al., 2011). Espera-se, desta forma, que parte das unidades litoestratigráficas descritas para o Supergrupo Espinhaço Meridional também sejam apoiadas por novos dados geocronológicos. Um dos atributos das unidades cronoestratigráficas é o de que podem ser estendidas fora de sua seção ou área-tipo até onde for possível a observação dos critérios de equivalência de tempo, respeitando, contudo, as limitações de precisão impostas pelos critérios físicos (Petri et al. 1986).

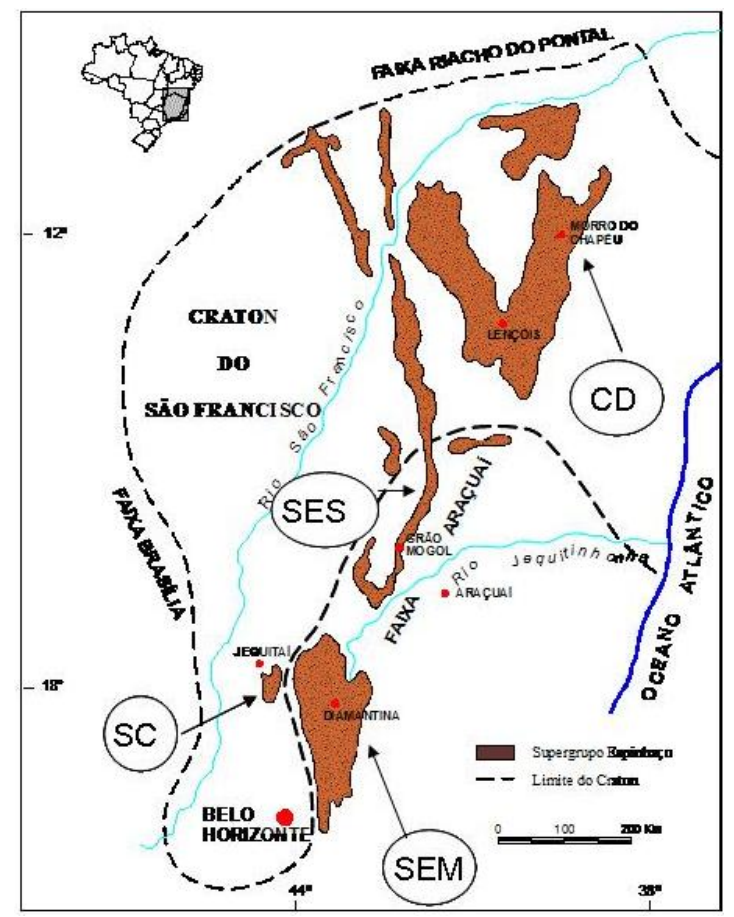

Figura 1. Esboço do Cráton São Francisco com a distribuição das unidades do Supergrupo Espinhaço nos estados de Minas Gerais e

Bahia, onde SC= Serra do Cabral, SEM = Serra do Espinhaço

Meridional, SES = Serra do Espinhaço Setentrional, $\mathbf{C D}=$ Chapada Diamantina (modificado de Chaves, 1997).

\section{BREVE SÍNTESE SOBRE A EVOLUÇÃO DO CONHECIMENTO ESTRATIGRÁFICO DO SUPERGRUPO ESPINHAÇO MERIDIONAL}

De todos os segmentos da cordilheira, a Serra do Espinhaço Meridional constitui o principal alvo dos estudos estratigráficos, estruturais e econômicos publicados até o presente (ver Renger, 1979; Uhlein, 1991; Renger \& Knauer, 1995; Chaves, 1997; Knauer 1999, 2007, dentre outros). Grande parte deste interesse foi motivada inicialmente pela descoberta de diamantes associados aos metaconglomerados da Formação Sopa-Brumadinho no século XVIII, atingindo o auge de sua exploração no século XIX.

Aos trabalhos pioneiros de Eschwege (1822, 1833) seguiram-se inúmeras contribuições para o esboço estratigráfico desta parcela da serra (e.g. Derby, 1906; Moraes \& Guimarães, 1930; Moraes et al., 1937), culminando com as obras de Pflug (1965, 1968), reconhecendo a Serra do Espinhaço Meridional como uma entidade geotectônica (primeiramente proposta por Barbosa, 1954) e, ao mesmo tempo, propõe a subdivisão segundo o modelo faciológico da teoria geossinclinal: miogeossinclinal (região de Diamantina), zona de transição (região de Itabira) e eugeossinclinal (região de Guanhães).

Estudos estratigráficos mais detalhados na região miogeossinclinal ("Fácies Diamantina") levaram Pflug $(1967,1968)$ à definição das oito unidades estratigráficas fundamentais para o Supergrupo Espinhaço Meridional, formações designadas, da base para o topo, de: São João da Chapada, SopaBrumadinho, Galho do Miguel, Santa Rita, Córrego dos Borges, Córrego Bandeira, Córrego Pereira e Rio Pardo Grande (Fig. 3). Estas unidades serviram de referência para os diversos estudos litoestratigráficos posteriores (e.g. Schöll \& Fogaça, 1979; Dossin et al., 1984, 1990; Garcia \& Uhlein, 1987; Knauer, 1990; Almeida-Abreu, 1993; MartinsNeto, 1993).

A coluna estratigráfica regional de Fogaça (1995), aplicada para toda região ocupada pela Folha Diamantina (1:100.000), baseiou-se nos trabalhos de Pflug $(1965,1968)$, com as modificações propostas por Schöll \& Fogaça $(1979,1981)$ e Fogaça et al. (1984). As modificações se concentram apenas em designações novas para: (1) a subdivisão do Supergrupo Espinhaço em dois grupos (Dossin et al., 1985 e Almeida-Abreu, 1993); (2) denominações formais dos membros da Formação SopaBrumadinho, propostos por Almeida-Abreu (1993) em lugar dos níveis de Schöll \& Fogaça (1979). Não é adotada a inclusão da Formação Bandeirinha (Grupo Costa Sena, Supergrupo Rio Paraúna) no Supergrupo Espinhaço, conforme proposto por Almeida-Abreu (1993, in Knauer 1999).

As propostas estratigráficas para o Supergrupo Espinhaço baseadas no empilhamento litoestratigráfico e, principalmente as interpretações dela decorrentes, perduraram até o início dos anos de 1990, quando os primeiros estudos sobre "Estratigrafia de Seqüências" começaram a ser aplicados nos metassedimentos que compõem a Serra do Espinhaço Meridional (e.g. Silva, 1995; Dupont, 1995). O Supergrupo Espinhaço (senso lato) provavelmente remonta a uma história geológica antiga demais para que seja considerado apenas um 
único e simples cenário de embaciamento sedimentar, aliado à grande extensão geográfica para a qual foi empregada, sem nenhum estudo apropriado de correlação estratigráfica em que pudesse ser feita uma integração regional sistemática.

Um dos pontos importantes nessa nova abordagem diz respeito ao reconhecimento de discordâncias ou superfícies de descontinuidades regionais. Em muitos casos, uma superfície de discordância regional chega a acumular tempo bem maior que os próprios intervalos deposicionais presentes acima ou abaixo dela; de forma alternativa, podem separar tratos estratigráficos gerados em condições genéticas distintas. Cada um dos ciclos limitados por discordâncias expressa um processo geodinâmico específico, responsável pela sua origem, cuja magnitude é definida pela "ordem hierárquica" em que ocupa na pirâmide estratigráfica.

Nesse cenário, Martins-Neto (2000, 2007) definem um "Ciclo Espinhaço de $1^{\text {a }}$ Ordem" para toda a seqüência de metassedimentos do Supergrupo Espinhaço, compreendendo um rifte abortado preenchido entre cerca de 1.73 a $1.5 \mathrm{Ga}$. A bacia Espinhaço compreende quatro ciclos de $2^{\text {a }}$ Ordem (pré-rifte, rifte, transicional e flexural), subdivididas em seqüências menores de $3^{\mathrm{a}}$ Ordem.

\section{GEOCRONOLOGIA U-Pb DO SUPERGRUPO ESPINHAÇO MERIDIONAL}

Foram realizados

levantamentos sedimentológicos-estratigráficos detalhados nas regiões de Guinda-Sopa, Extração e "Altitude Máxima", tendo a Formação Galho do Miguel como datum estratigráfico regional (Santos et al., prep..), acrescidos do Grupo Conselheiro Mata na região homônima (Fig. 2). Estes levantamentos serviram de referência para a amostragem visando a retirada e datação de zircões, detríticos nas unidades de origem sedimentar, ígneos nos corpos de mesma natureza.

Os dados de zircões detríticos de toda seção, desde a Formação Bandeirinha até o topo do Grupo Conselheiro Mata definem o conjunto de três populações de zircões entre o período $1,8 \mathrm{Ga}$ e 0,9 Ga (Fig. 3).

Os dados de campo combinados com datações sistemáticas de zircões detríticos retirados dos metasssedimentos das formações Bandeirinha, São João da Chapada e Sopa-Brumadinho (Chemale Jr. et al., 2011), evidenciam a presença de dois conjuntos distintos de preenchimento bacinal para o Supergrupo Espinhaço Meridional (Figura 4).

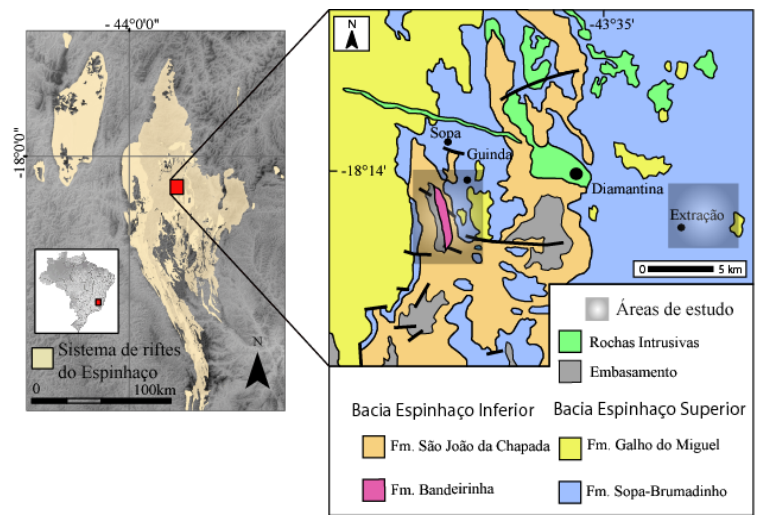

Figura 2. Mapa de localização das áreas de levantamentos de detalhe e amostragem na Serra do Espinhaço Meridional (modificado de Chaves, 1997).

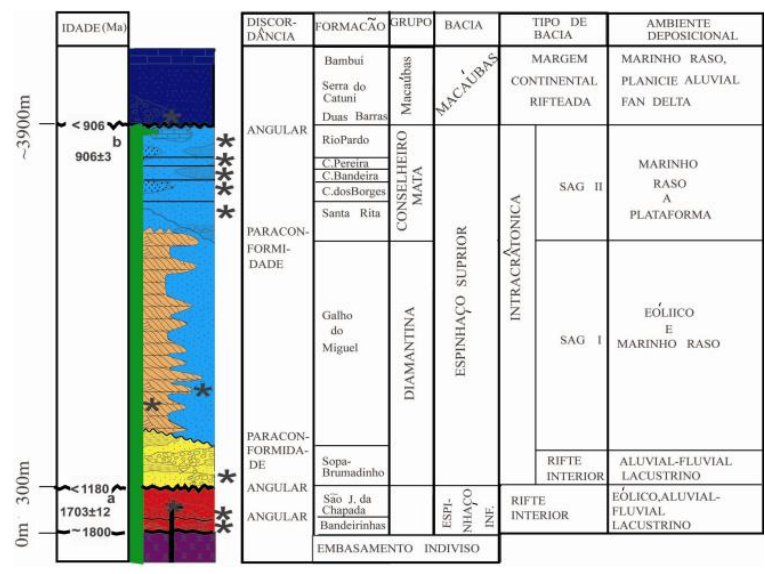

Figura 3. Carta estratigráfica do Supergrupo Espinhaço (modificado de Dossin et al., 1990, Martins-Neto, 2000, Alkmim et al. 2006) com a localização das amostras analisadas por Chemale et al. (2011). (*). a = segundo Machado et al. (1989); $b=$ Chemale et al. (2011).

As formações Bandeirinha e São João da Chapada (Figura 5A, 5B) apresentam zircões detríticos e intrusões de corpos ígneos conhecidos regionalmente como "filitos hematíticos" (Figs. 5C e 5D). Tanto os zircões de origem detrítica, como os zircões ígneos retirados do filito hematítico, apresentam um mesmo conjunto de idade, datados

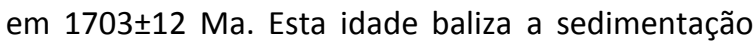
das formações Bandeirinha e São João da Chapada, posicionadas entre 1,80 a 1,68 Ga (Chemale et al., 2011). Por meio de cartografia geológica de alta resolução, em escala de 1:100 a 1:3.000 (Santos et al., em prep.), é possível determinar que a Formação Bandeirinha é indivisa.

A Formação Sopa-Brumadinho (figuras $6 \mathrm{~A}$ e $6 B$ ), até então colocada a partir de uma seção basal de pelitos (Nível "D" de Schöll \& Fogaça, 1979), foi redefinida, visto que os pelitos pertencem na sua maior parte aos depósitos fluviais-lacustres da seção granodescrecente da Formação São João da Chapada. 
Nos trabalhos anteriores

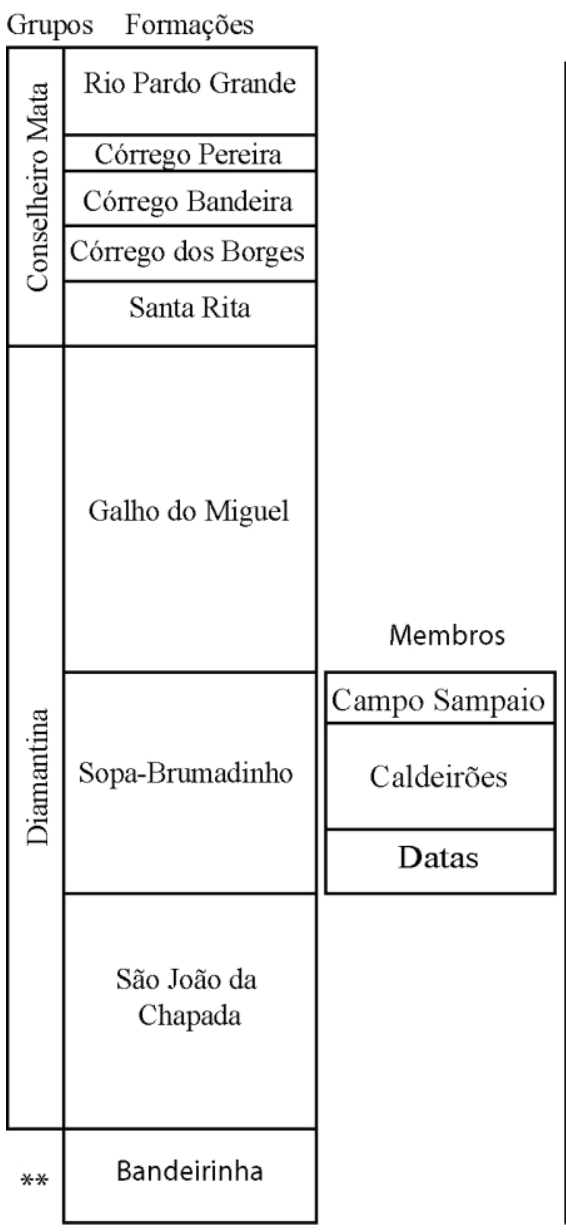

Intrusões

Estratificação plano-paralela

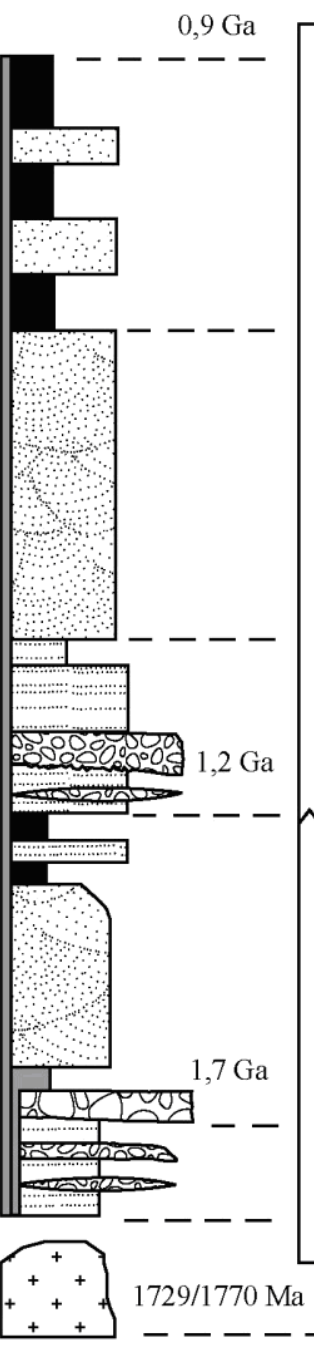

No presente trabalho*

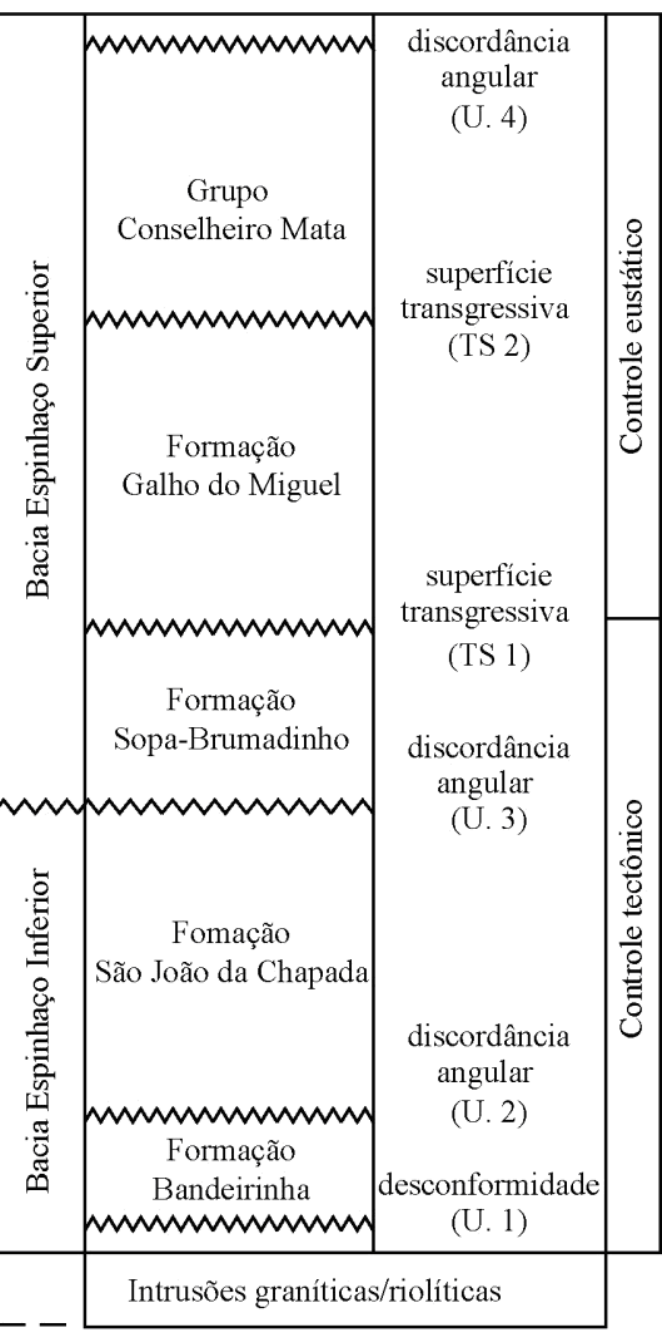

Conglomerado matriz suportado

Pelito

${ }^{+}$Granito/riolito

Figura 4. Disposição simplificada da estratigrafia do Supergrupo Espinhaço Meridional. O rifte é dividido em duas bacias. Compilação e modificações a partir dos trabalhos de Pflug (1968), Schöll \& Fogaça (1979) e Dossin et al. (1984). *Conforme proposto por Santos et al. (em prep.). **Unidade adicionada por Almeida-Abreu (1993). Fora de escala.
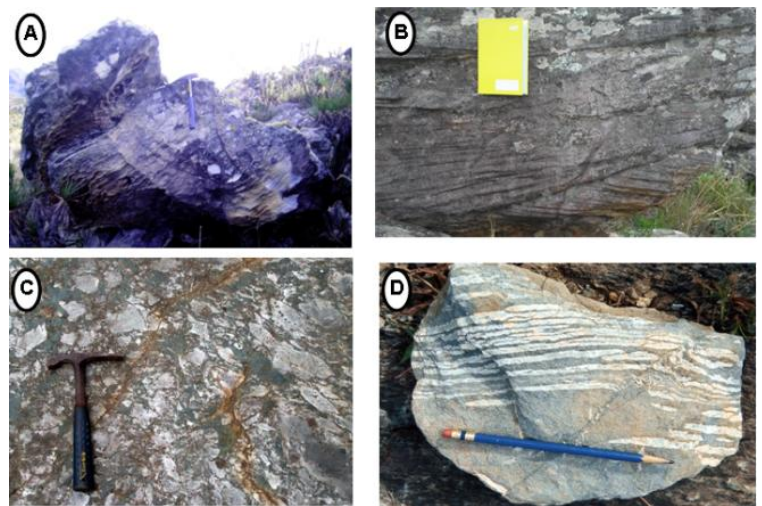

Figura 5. A) Quartzito da Formação São João da Chapada com lentes de conglomerado polímitico suportado pela matriz (base do Supergrupo Espinhaço). B) Formação São João da Chapada representada por quartzitos com estratificações cruzadas acanaladas, de médio porte. C) e D). Feições em afloramento e em amostra de mão do filito hematítico, com feição de rocha vulcânica a vulcanoclástica de composição potássica, intraplaca (Dussin \& Dussin, 1995).

A passagem dos níveis pelíticos para a sedimentação arenosa a conglomerática da Formação Sopa-Brumadinho se dá por uma discordância angular, marcada por uma diferença de aproximadamente 10 graus no acamamento entre as duas unidades (Santos et al., em prep., Fig. 7). Os zircões detríticos mais jovens apresentam idades mais novas que $1.2 \mathrm{Ga}$ (Chemale Jr. et al., 2011, Fig. 8). 

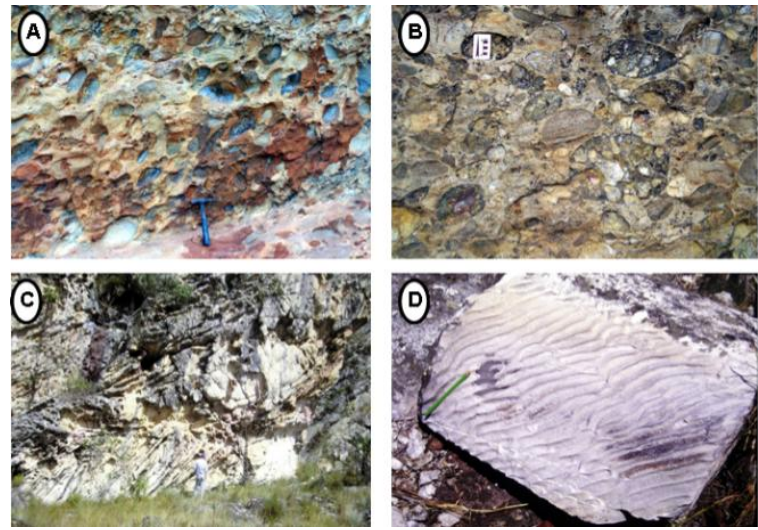

Figura 6. A) Formação Sopa-Brumadinho representada por depósitos aluviais com conglomerado polímitico suportado por seixos. B) Detalhe do conglomerado com seixos de variadas fontes, incluindo seixos de conglomerados. C) Formação Galho do Miguel, interpretada como parte da transição entre o rifte (ex. Fomações S. J. da Chapada e Sopa-Brumadinho) e as unidades marinhas superiores, com quartiztos com megaestratificações cruzadas tabulares. D) Detalhe da Formação Galho Miguel com marcas de ondas assimétricas.

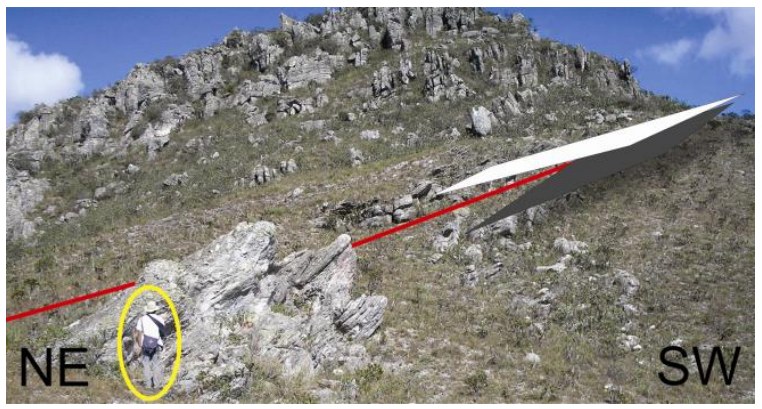

Figura 7. Discordância angular entre a Formação São João da Chapada e a Formação Sopa-Brumadinho. Serra da Miúda.

\section{DISCUSSÕES E CONCLUSÕES}

Nos últimos anos, com a utilização de datação de zircões detríticos, pode-se entender as unidades do Supergrupo Espinhaço não como uma bacia simples, mas como uma sequência de ciclos deposicionais em um ambiente intraplaca em uma área cratônica, que apontam para a geração de três ciclos deposicionais ou bacias principais (Chemale Jr. et al., 2011), o Espinhaço Inferior (1,80 Ga a 1,68 Ga), o Médio (1,60 Ga- 1,35 Ga) e o Superior (1,19 Ga a 0,91 Ga).

A presença do ciclo intermediário do Supergrupo Espinhaço (1,6 Ga - 1,3 Ga) está bem documentada na Chapada Diamantina (Danderfer et al., 2009). No entanto, no Supergrupo Espinhaço Meridional, Chemale Jr. et al. (2011) não encontraram o registro direto desta sedimentação, o que levou a estes autores interpretar que durante a deposição deste ciclo a atual região da Serra do Espinhaço Meridional comportou-se como um alto estrutural ou área de não deposição.
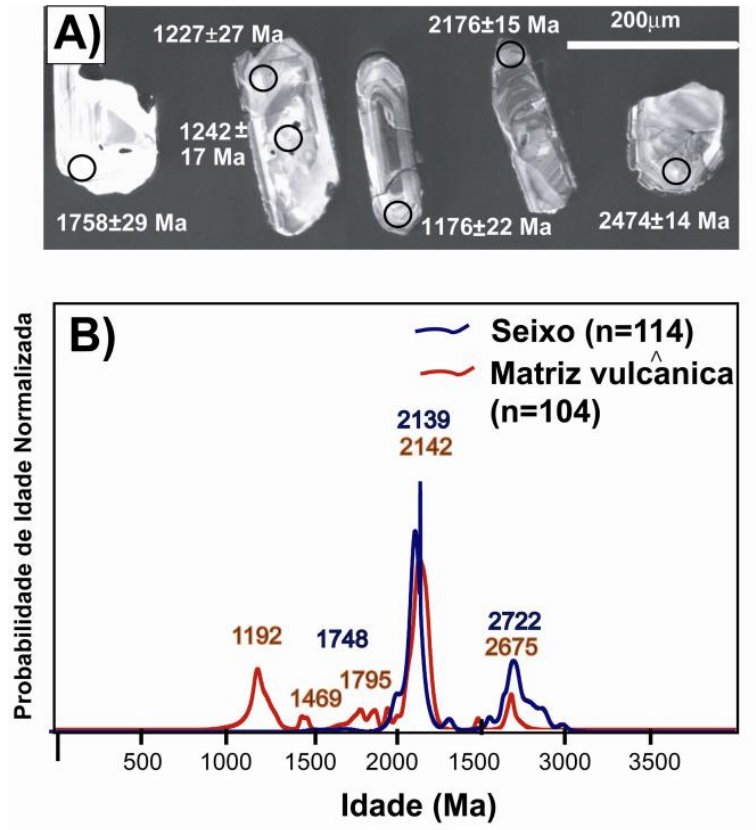

Figura 8. A) Imagem de catodoluminescência dos zircões analisados de $\sim 1,2 \mathrm{Ga}, 1,7 \mathrm{Ga}, 2,1 \mathrm{Ga} e$ 2,5 Ga da matriz verde do metaconglomerado diamantífero da Formação SopaBrumadinho, localizado na região de Extração. B) Histograma de probabilidade relativa com dados de U-Pb em zircão de seixos $e$ matriz verde (com composição dacítica) (Chemale et al., 2011).

Os dados geocronológicos das formações Bandeirinha e São João da Chapada sugerem que estas unidades tenham sido depositadas durante o Estateriano (1,68 a 1,80 Ga), os quais são colocados até o momento na "Bacia do Espinhaço Inferior". A porção de topo da Formação São João da Chapada, anteriormente atribuída à Formação SopaBrumadinho (Nível “D” de Schöll \& Fogaça 1979), é caracterizada por uma sequência granodecrescente clássica. A passagem entre as formações São João da Chapada e Sopa-Brumadinho é dada localmente por uma superfície de discordância angular.

As novas idades de U-Pb em zircões detríticos e magmáticos apresentadas por Chemale Jr. et al. (2011) permitem uma nova visão sobre a história evolutiva da Bacia Espinhaço. As idades U-Pb da seção basal da Fm. Sopa-Brumadinho, com pico em $1192 \mathrm{Ma}$, e intrusão de diques máficos da Suíte Pedro Lessa (Machado et al., 1989), que cortam as unidades do Supergrupo Espinhaço (com idade próxima a 0,9 Ga), são definitivas para estabelecer uma idade Esteniana-Toniana para a porção superior da Bacia Espinhaço. Por meio do exame desta seção, compreendida pelas formações Sopa-Brumadinho e Galho do Miguel e pelo Grupo Conselheiro Mata, conclui-se que cerca de $85 \%$ de todo o pacote sedimentar atribuído ao Supergrupo Espinhaço Meridional foi depositado durante este período, temporalmente coincidente com o Ciclo Grenviliano. 
Pelo exposto acima, conclui-se, portanto, que o Supergrupo Espinhaço Meridional é formado por duas grandes sucessões sedimentares separados por nítida discordância angular, interpretada como dois ciclos de preenchimento de bacia: (1) o primeiro Estateriano (1,78 to $1,70 \mathrm{Ga})$, interpretado como rifte intracontinental, (ii) outro Esteniano-Toniano (1,18 to $0,91 \mathrm{Ga}$ ) como uma bacia intracratônica cujo processo inicial de subsidência ocorreu por implantação de um rifte.

\section{AGRADECIMENTOS}

Ao projeto PETROBRÁS-Fundep "Geologia Estrutural e Estratigrafia do Sistema EspinhaçoChapada Diamantina e sua aplicação nas Bacias Mesocenozóicas da Margem Passiva Brasileira" por todo o suporte fornecido para o desenvolvimento das atividades de campo e de laboratório. A todos os colegas que contribuíram direta e indiretamente para os resultados aqui apresentados. Ao colega Carlos Maurício Noce, geólogo ilustre e grande incentivador das pesquisas à luz do conhecimento científico moderno.

\section{REFERÊNCIAS BIBLIOGRÁFICAS}

Alkmim F.F. 2004. O que faz de cráton um cráton? O Cráton do São Francisco e as revelações Almeidianas ao delimitá-lo. In: V. Mantesso Neto, A. Bartorelli, C. Dal Ré Carneiro e B. Brito Neves (orgs.) Geologia do Continente Sul-Americano: evolução da obra de Fernando Flávio Marques Almeida. São Paulo; Editora Beca, 17-35.

Almeida-Abreu P.A. 1993. A evolução geodinâmica da Serra do Espinhaço Meridional, Minas Gerais, Brasil. Tese de doutoramento, Univ. Freiburg, 150p.

Almeida-Abreu P.A. 1995. O Supergrupo Espinhaço da Serra do Espinhaço Meridional. Minas Gerais: o rifte, a bacia e o orógeno. Geonomos, 3(1): 1-18.

Almeida-Abreu P.A. \& Renger F. 2002. Serra do Espinhaço meridional: um orógeno de colisão Mesoproterozóico. Rev. Bras. Geoc., 32/1: 1-14.

Barbosa O. 1954. Evolution du geossinclinal Espinhaço, In: Inter. Geol. Congr., Comtes. Rendus, section XIII, 19e session: 1 37, 1952, Argélia.

Brito Neves B.B., Cordani U.G., Kawashita K., DelhalL J. 1979. A evolução geocronológica da Cordilheira do Espinhaço - dados novos e integração. Rev Bras. Geoc., 9(1): 71-85.

Brito Neves B.B.; Sá J.M.; Nilson A.A; \& Botelho N.F. 1995: A Tafrogênese Estateriana nos blocos paleoproterozóicos da América do Sul e processos subseqüentes, Geonomos, 3(2): pp. 1-21.

Chaves M.L.S.C. 1997. Geologia, mineralogia e gemologia do diamante da Serra do Espinhaço em Minas Gerais. Tese de doutoramento, IG-USP, São Paulo. 289p.

Chemale Jr. F., Rosière C.A. \& Endo I. 1991: Evolução tectônica do Quadrilátero Ferrífero, Minas Gerais: um modelo, Pesquisas, 18(2): 104-127.

Chemale Jr. F., Dussin I.A., Alkmim F.F., Martins M.S., Queiroga G. Santos M.N. 2011. Unravelling a Proterozoic basin history through detrital zircon geochronology: The case of the
Espinhaço Supergroup, Minas Gerais, Brazil. Gondwana Research (in press)

Danderfer-Filho A. 2000. Geologia sedimentar e evolução tectônica do Espinhaço Setentrional, Estado da Bahia. Tese de doutorado, UnB, Brasília, 498p.

Danderfer A., de Waele B., Pedreira A.J., Nalini H.A. 2009. New geochronological constraints on the geological evolution of Espinhaço basin within the São Francisco Craton-Brazil. Precambrian Research, 170: 116-128.

Derby O.A. 1906. The Serra do Espinhaço, Brazil - Jour. Geol., 14: 374-401, Chicago.

Dossin I.A., Uhlein A., Dossin T.M. 1984. Geologia da Faixa Móvel Espinhaço em sua porção meridional, MG. In: XXXIII Cong. Bras. Geol., Anais 7: 3118-3134. Rio de Janeiro.

Dossin I.A., Chaves M.L. de S.C., Uhlein A. \& Alvarenga C.J.S. de. 1985. Geologia e Depósitos Diamantíferos da Região de Sopa, Diamantina (MG)., III Simp.Geol. Minas Gerais, BH, Bol. 5: 276 -290 .

Dossin I.A., Dossin T.M., Chaves M.L.S.C. 1990. Compartimentação estratigráfica do Supergrupo Espinhaço em Minas Gerais - Os grupos Diamantina e Conselheiro Mata. Revista Bras. Geociências, 20(1-4): 178-186.

Dupont H. 1995. O Grupo Conselheiro Mata no seu quadro palogeográfico e estratigráfico. In: Simp. Geol. Minas Gerais, 8. Diamantina, 1995. Anais.Belo Horizonte, SBG-Núcleo MG, 9-10pg.

Dussin I.A. \& Dussin T.M. 1995. Supergrupo Espinhaço: Modelo de Evolução Geodinâmica. Geonomos, 1: 19-26.

Eschwege W.L.von 1822. Geognostisches Gemälde von Brasilien und warscheinliches Muttergestein der Diamanten, LandesIndustrie-Comtoir, Weimar, $44 \mathrm{p}$.

Eschwege W.L. von 1833. Pluto brasiliensis - Tradução em português, 2 vol., (Cia. Ed. Nac.), São Paulo, 1944.

Fogaça A.C.C. 1995. Geologia da Folha Diamantina. Projeto Espinhaço, COMIG/UFMG, 98 pp., Belo Horizonte.

Fogaça A.C.C., Almeida-Abreu P.A. \& Schorscher H.D. 1984. Estratigrafia da seqüência supracrustal arqueana da porção meridiana-central da Serra do Espinhaço Meridional, Minas Gerais. In: XXXIII Cong. Bras. Geol., 6: 2654-2667, Rio de janeiro.

Garcia A.J.V. \& Uhlein A. 1987. Sistemas deposicionais do Supergrupo Espinhaço na região de Diamantina (MG), 1은 Simp.Sistemas Depós. no Precambr. (Ouro Preto, SBG/MG, 6: p. $113-136$.

Knauer L.G. 1999. Serra do Espinhaço Meridional: considerações sobre a estratigrafia e análise da deformação das unidades proterozóicas. Tese de Doutoramento, IGCE/UNESP, Rio Claro, 324p.

Knauer L.G. 2007. O Supergrupo Espinhaço em Minas Gerais: considerações sobre sua estratigrafia e seu arranjo estrutural. Geonomos, 15(1): 81-90.

Machado N., Schrank A., Abreu F.R., Knauer L.G. \& Almeida-Abreu P.A. 1989. Resultados preliminares da geocronolgia U/Pb na Serra do Espinhaço Meridional. V Simp. Geol. Minas Gerais, Anais, p.171-174, Belo Horizonte.

Moraes L.J. \& Guimarães D. 1930. Geologia da região diamantífera do Norte de Minas Gerais - An. Acad. Bras. Cienc.,_2: 153-186, Rio de Janeiro.

Moares L.J., Barbosa O., Lisboa J.M.A., Lacourt F., Guimarães D. 1937. Geologia Econômica do Norte de Minas Gerais. Boletim DNPM/SFPM. 19: 191p. Rio de janeiro. 
Martins-Neto M.A. 1993. The sedimentary evolution of a Proterozoic rift: the basal Espinhaço Supergroup, Minas Gerais, Brazil. Univ. Freiburg, Tese de Doutorado, 155p.

Martins-Neto M.A. 2000. Tectonics and sedimentation in a Paleo/Mesoproterozoic Rift-Sag Basin (Espinhaço Basin, southeastern Brazil). Prec. Res. 103: 147-173 .

Martins-Neto M.A. 2007. Sequence stratigraphic framework of Proterozoic successions in eastern Brazil. Marine and Petroleum Geology, doi:10.1016/j.marpetgeo.2007.10.001

Petri S., Coimbra A.M., Amaral G., Ojeda H.O., Fúlfaro V.J., Ponçano W.P. 1986. Código Brasileiro de nomenclatura estratigráfica. Rev. Bras. Geoc., 16: 372-376.

Pflug R. 1965. A geologia da parte meridional da Serra do Espinhaço e zonas adjacentes, Minas Gerais DNPM, Div. Geol. Min., Bol. 226., 51p., Rio de Janeiro.

Pflug R. 1968. Observações sobre a estratigrafia da Série Minas na região de Diamantina, Minas Gerais - DNPM, Div. Geol. Min. Not. Prel. Estud., 142, 20 p., Rio de Janeiro.

Renger F. 1979. Evolução dos conceitos geológicos da Serra do Espinhaço. In: Simp. Geol. Minas Gerais, I, Diamantina-MG, An., 9-27.

Renger F.E. \& Knauer L.G. 1995. Espinhaço Quo vadis? (onde está? Onde vai?) - A evolução dos conhecimentos sobre a cordilheira do Espinhaço Meridional em Minas Gerais entre 1979 e 1995. Geonomos. 3:31-39.

Santos M.N., Chemale Jr. F., Dussin I.A., Martins M., Assis T. A.R., Jelinek A.R. \& Guadagnin F. Sedimentological and
Paleoenvironmental Constraints of the Precambrian Espinhaço Rift System, Brazil. (em preparação)

Schobbenhaus C. 1993. O Proterozóico Médio no Brasil com ênfase à região Centro-leste, uma revisão. Freiburg, Univ. Freiburg, Tese Doutorado, 166p

Schobbenhaus C. \& Brito Neves B.B. 2003. A geologia do Brasil no contexto da Plataforma Sul-Americana. In: L.A. Bizzi, R.M. Vidotti e J.H. Gonçalves (eds.). Geologia, Tectônica e Recursos Minerais do Brasil. Brasília: CPRM, Serviço Geológico do Brasil, 5-54.

Schöll W. \& Fogaça A.C.C. 1979. Estratigrafia da Serra do Espinhaço na região de Diamantina. In: I Simp. Geol. Minas Gerais, Anais, p. 55- 73.

Silva R.R. 1995. Contribution to the stratigraphy and paleogeography of the lower Espinhaço Supergroup (Mesoproterozoic), between Diamantina and Gouveia, Minas Gerais State, Brazil, Tese de Doutorado, Freiburg Geowiss.Beitr., Band 8: 115p, Feiburg.

Silva L.L. 2008. Relação estratigráfica e estrutural entre o Grupo Costa Sena e Guinda na região de Diamantina, Minas Gerais. Dissertação de Mestrado, IGC/UFMG, 164p.

Uhlein A. 1991. Transição Cráton-Faixa Araçuaí (Ciclo Brasiliano) no estado de Minas Gerais. Aspectos estratigráficos e estruturais. IG/USP, São Paulo. Tese de Doutoramento, 259p.

Uhlein A., Trompette R. \& Egydio-Silva M.E. 1995. Rifteamentos superpostos e tectônica de inversão da borda sudeste do Cráton do São Francisco. Geonomos, 3(1): 99-107. 